\title{
DIREITO À ACESSIBILIDADE NAS CIDADES PARA AS PESSOAS COM DEFICIÊNCIA E/OU MOBILIDADE REDUZIDA: ESTUDO DE UM CASO - CIDADE DE BAURU - SÃO PAULO.
}

Flávia Piva Almeida Leite ${ }^{1}$

\begin{abstract}
Resumo:
Esta pesquisa objetivou verificar se o poder público municipal de Bauru, na prática tem efetivado e garantido o direito a acessibilidade nos seus espaços públicos. A metodologia utilizada neste levantamento foi uma pesquisa bibliográfica e documental descritiva, junto a Constituição federal, as leis brasileiras e, leis do município de Bauru que asseguram o direito à acessibilidade para as pessoas com deficiência e/ou mobilidade reduzida, além de uma observação sistemática - via coleta de fotos em alguns espaços da cidade de Bauru.
\end{abstract}

Palavras-chave:

Pessoa com deficiência; pessoa com mobilidade reduzida; direito à acessibilidade; acessibilidade ao meio físico na cidade de Bauru.

\section{RIGHT TO ACCESSIBILITY IN CITIES FOR PEOPLE WITH DISABILITIES AND/OR REDUCED MOBILITY: A CASE STUDY - CITY OF BAURU - SÃO PAULO.}

\begin{abstract}
:
This research aimed to verify if the municipal government of Bauru, in practice, has implemented and guaranteed the right to accessibility in its public spaces. The methodology used in this survey was a descriptive bibliographic and documentary research, along with the Federal Constitution, Brazilian laws and laws of the municipality of Bauru that ensure the right of accessibility for people with disabilities and / or reduced mobility, in addition to systematic observation - via photo collection in some spaces in the city of Bauru.
\end{abstract}

\section{Keywords:}

Disabled person; person with reduced mobility; right to accessibility; accessibility to the physical environment in the city of Bauru.

Doutora em Direito Urbanístico pela Pontifícia Universidade Católica - PUC - São Paulo/SP, Mestre em Direito Constitucional pela Instituição Toledo de Ensino - ITE - Bauru/SP, Pós-graduada em Gerente de Cidades pela Fundação Armando Álvares Penteado - FAAP - São Paulo/SP, Graduada em Direito pela ITE- Bauru. Docente da UNESP - Universidade Estadual Paulista "Júlio de Mesquita Filho", Faculdade de Arquitetura, Artes e Comunicação - Campus Bauru. Docente permanente do Programa de Pós-Graduação em Direito da UNESP- Franca. E-mail: flavia.leite@unesp.br 


\section{INTRODUÇÃO}

Segundo dados estatísticos do Censo do IBGE de 2010, cerca de mais de $81 \%$ da população brasileira vivem em cidades, consequentemente, não há a menor dúvida que o Brasil é um País urbano. Aponta o mesmo órgão que 23,9\% da população brasileira apresentam algum tipo de deficiência, totalizando aproximadamente 45,6 milhões de pessoas. É importante salientar que esses números se referem somente ao total das deficiências, não considerando as pessoas com restrição de mobilidade (idosos, obesos, gestantes, anões, dentre outras).

Todavia, viver nas cidades continua sendo um grande transtorno e também um desafio para a pessoa com deficiência que, por exemplo, ao se movimentar pelos seus espaços depara-se, invariavelmente, com incontáveis obstáculos físicos, que as impedem de exercer seus direitos em igualdade de condições com as demais pessoas.

Portanto, não mais se concebe que hoje espaços mobiliários, equipamentos, urbanos, edificações, transportes, informação e comunicação, inclusive os sistemas e tecnologias (governo-egov.), bem como de outros serviços e instalações abertos ao público ou privados de uso coletivo, tanto na zona urbana como na rural, fiquem a reboque da conveniência ou mesmo na negligência do administrador público, bem como da sociedade, ao não contemplar em suas obras ou projetos as normas que dispõem sobre acessibilidade.

A acessibilidade aos edifícios e logradouros públicos, no transporte coletivo e nas suas mútuas interações é regra mínima e básica de cidadania, tanto que, o constituinte materializou-a no artigo 227, § $2^{\circ}$ e no artigo 244. Para dar eficácia a esses dispositivos constitucionais, foram editadas, dentre outras, a Lei 7.853/89, o Decreto $\mathrm{n}^{\circ} 3.29899$, as Leis $\mathrm{n}^{\circ} 10.04800$ e $\mathrm{n}^{\circ} 10.09800$ e o Decreto $\mathrm{n}^{\circ}$ 5.29604. De uma maneira geral, toda essa legislação visa garantir a pessoa com deficiência a plena integração social e acessibilidade aos espaços públicos da cidade.

A Constituição, ao ter ratificado a Convenção sobre os Direitos das Pessoas com Deficiência e seu Protocolo Facultativo, determinou que o Estado deverá empreender todos os seus esforços para garantir a acessibilidade, para que se promova a igualdade de todos, em cumprimento aos fundamentos da República, de cidadania e dignidade da pessoa humana, o que se realizará pela definição de meios para que eles sejam atingidos.

O direito à acessibilidade é, portanto, uma exigência constitucional que surge, atualmente, como um direito fundamental, sobretudo, para a pessoa com deficiência. Para 
que elas possam realizar de modo pleno e irrestrito esse direito fundamental e compartilhar os aspectos positivos da urbanização, é essencial que lhes assegure a capacidade de circular pela cidade, na qual se desenvolve parcela significativa de suas vidas. Para cumprir o objetivo de garantir a acessibilidade para as pessoas com deficiência, o legislador ordinário produziu, no ano de 2015, a Lei n. 13.146, que é o Estatuto da Pessoa com Deficiência, a Lei Brasileira de Inclusão.

É fato que o Município é o principal responsável pela tomada de decisões e das ações executivas das políticas de acessibilidade. Esse dever advém, dentre outras fontes, das competências estabelecidas nos artigos 30, I, VIII e 182, todos da Constituição Federal. O Estatuto da Cidade (Lei $n^{\circ} 10.257 / 2001$ ) reconheceu o papel fundamental dos municípios na formulação e condução do processo de gestão das cidades, estabelecendo diretrizes para nortear a elaboração de políticas públicas urbanas. Consolidou e ampliou a competência jurídica da ação municipal.

Diante desse dever, a pesquisa teve por objetivos: - analisar a doutrina e as legislações tanto no plano constitucional, infraconstitucional e, especificamente as leis do Município de Bauru que asseguram o direito a acessibilidade para as pessoas com deficiência; e- verificar de que maneira o Poder Público municipal de Bauru, na prática tem efetivado esse direito -via observação empírica em área determinada - para as pessoas com deficiência em seus espaços públicos.

Para atingir tais objetivos valeu-se de duas etapas de investigação. A primeira, referente ao levantamento bibliográfico e análise de doutrinas e legislações no âmbito constitucional, infraconstitucional a partir da Constituição Federal de 1988 e, leis do Município de Bauru no período de 1999 a 2020 que resultou no diagnóstico comparativo das condições de acessibilidade na cidade de Bauru, no que tange às barreiras/obstáculos físicos, que acabam por impedir as pessoas com deficiências de ir, vir e circular de maneira livre e autônoma em igualdade de condições com as demais pessoas. Na segunda etapa deste estudo, a observação empírica sistemática, foi feita com fotos e fichas cadastrais para compilar, avaliar e identificar a atual situação dos projetos implantados e/ou adaptados com observância do desenho universal do espaço público de Bauru, circunscrito a uma área de cerca de $2 \mathrm{~km}$ de raio da região central desta cidade, no período de junho a agosto de 2019, nas seguintes variáveis: presença de faixas para orientar as pessoas com deficiência visual, de pisos 
adequados para quem utiliza cadeiras de rodas ou bengalas, de degraus ou rampas com corrimão e, de acesso facilitado para ingressar nas calçadas e logradouros.

\section{DIREITO À ACESSIBILIDADE: CONSIDERAÇÕES SOBRE A NORMATIZAÇÃO NOS ESPAÇOS URBANOS NO BRASIL}

À toda pessoa é garantido o direito de ir e vir; esse direito vem assegurado como um dos direitos fundamentais previsto no artigo 5, inciso XV, da nossa Constituição Federal de 1988. O direito de locomoção é a possibilidade ampla que tem o indivíduo de circular livremente, conforme seu desejo. Nesse sentido, José Afonso da Silva (2009, p. 111), afirma que o direito de locomoção implica o de circulação. Ele conceitua o direito de circulação como a "faculdade de deslocar de um ponto a outro através de uma via pública ou afetada ao uso público."

Todavia, esse deslocamento de forma autônoma e sem barreiras pelos espaços da cidade não tem sido uma realidade para as pessoas com deficiência. Afinal, ao longo dos anos, as cidades foram construídas e projetadas sem considerar a diversidade humana e, continuam fisicamente inacessíveis. Arquitetos e engenheiros utilizam em seus projetos a escala humana ideal como medida de referência (método Vitruviano) ${ }^{2}$. As cidades contemplaram e continuam a contemplar em seus projetos o indivíduo perfeito, de preferência jovem, forte e no ápice de seu vigor físico - com plenas capacidades físicas e sensoriais. Esquecem que qualquer indivíduo, a qualquer momento de sua vida, poderá ter sua mobilidade reduzida, até mesmo em consequência do envelhecimento. Determinadas pessoas não são vistas em nossas cidades porque postos de saúde são construídos, ainda sem rampas, calçadas sem rebaixamento na maior parte das vias de circulação, praças totalmente inacessíveis, transportes públicos sem adaptação adequada, falta de acesso aos meios de comunicação e à tecnologias dentre tantas outras dificuldades, sendo projetados e construídos em total desacordo com as normas que dispõem sobre a acessibilidade e, por conseguinte, sem a prática do desenho universal.

\footnotetext{
${ }^{2}$ Marcus Vitruvius Pollio, ou Vitruvio ( \pm 40 a.C.), segundo anota Silvana Serafino Cambiaghi, em sua obra Desenho Universal - métodos e técnicas para arquitetos e engenheiro, p. 39 (2007) viveu no século I a C. O engenheiro romano apresenta em sua obra De Architectura, um modelo ideal para o ser humano, segundo determinado raciocínio matemático e baseando-se, em parte, na divina proporção. Na descrição feita pelo arquiteto, as diferentes partes do corpo formam um conjunto harmonioso de proporções. A arquitetura deveria seguir a mesma concepção, isto e, considerar a proporcionalidade entre as partes para completar o todo harmoniosamente. Os seus padrões serviram de fonte inspiradora a diversos textos sobre construção e arquitetura.
} 
A questão da acessibilidade não é um tema tão recente. No Brasil, tal como acontece em muitos países, começou a ser abordado a partir de 1981, quando foi declarado o Ano Internacional dos Portadores de Deficiência pelas Nações Unidas. No ano de 1985, o Brasil publicou a primeira norma técnica sobre o tema - a NBR 90501985 - Adequação das Edificações e do Mobiliário Urbano à Pessoa Deficiente, elaborada pela comissão de estudos do Comitê Brasileiro da Construção Civil, da Associação Brasileira de Normas Técnicas.

Após três anos, foi promulgada a Constituição Federal de 1988, que disciplina a acessibilidade, quando assegura, no artigo $227, \S 2^{\circ}$, que a Lei disporá sobre normas de construção dos logradouros e dos edifícios de uso público e de fabricação de veículos de transporte coletivo, a fim de garantir o acesso adequado às pessoas com deficiência, e, no artigo 244 complementa a citada norma, acrescentando que a lei disporá sobre a adaptação dos logradouros, dos edifícios de uso público e dos veículos de transporte coletivo atualmente existentes, a fim de garantir acesso adequado às pessoas portadoras de deficiência, conforme o disposto no artigo $227, \S 2^{\circ}$."

Atendendo a tal comando, foi publicada a Lei $\mathrm{n}^{\circ} 7.853 / 89$, que dispõe sobre o apoio às pessoas portadoras de deficiência, sua integração social, sobre a CORDE (Coordenadoria Nacional para Integração da Pessoa com Deficiência), e institui a tutela jurisdicional de interesses coletivos ou difusos dessas pessoas, disciplina a atuação do Ministério Público, define crimes, e dá outras providências.

O Decreto $\mathrm{n}^{\circ} 3.29899$ que regulamentou a Lei $\mathrm{n}^{\circ} 7.853 / 89$ trouxe como um dos objetivos da Política Nacional para Integração da Pessoa Portadora de Deficiência o acesso, o ingresso e a permanência delas em todos os serviços oferecidos à comunidade, estabelecendo em seu artigo $2^{\circ}$, parágrafo único, que os órgãos e entidades da administração direta e indireta devem dispensar tratamento prioritário e adequado para viabilizar medidas em diversas áreas, dentre as quais, a adoção e execução de normas que garantam a funcionalidade das edificações e vias públicas, que evitem ou removam os óbices às pessoas portadoras de deficiência e que permitam o acesso destas aos edifícios, logradouros e meios de transporte.

A acessibilidade foi novamente tratada pela lei $\mathrm{n}^{\circ}$ 10.048/00 que assegura tratamento prioritário às pessoas com deficiência, idosos, às gestantes, às lactantes e às pessoas acompanhadas por crianças de colo. Essa Lei obriga as repartições públicas, empresas concessionárias de serviço público e instituições financeiras a dispensar tratamento prioritário, por meio de serviços individualizados a essas pessoas, bem como sejam reservados assentos 
nos transportes coletivos; orienta ainda que compete às autoridades adotarem normas de construção e licenciamento para garantir acessibilidade em logradouros e sanitários públicos, bem como em edifícios de uso público e também, a acessibilidade nos meios de transportes.

A lei $\mathrm{n}^{\circ}$ 10.098/00 estabelece normas gerais e critérios básicos para promoção da acessibilidade das pessoas com deficiência ou com mobilidade reduzida, nas edificações públicas ou privadas, no espaço público, logradouros e seu mobiliário, nas comunicações e sinalização entre outros. O objetivo desta lei será alcançado quando forem suprimidas as barreiras e obstáculos nas vias e espaços públicos, no mobiliário urbano, na construção e reforma de edifícios e nos meios de transporte e de comunicação.

Após quatro anos foi publicado o Decreto $\mathrm{n}^{\circ}$ 5.296, de 02 de dezembro de 2004 que regulamentou as Leis $\mathrm{n}^{\circ} 10.048 / 00$, que dá prioridade de atendimento às pessoas que especifica e, a de $\mathrm{n}^{\circ}$ 10.09800, que estabelece normas gerais e critérios básicos para a promoção de acessibilidade das pessoas portadoras de deficiência ou com mobilidade reduzida.

A luta pela inclusão dessas pessoas em todos os segmentos da sociedade não parou. A ONU, preocupada com as sucessivas violações dos direitos humanos das pessoas com deficiência no mundo inteiro, conclui que esse grupo demandava uma atitude institucional da comunidade internacional, e, em 30 de março de 2007, em sua sede em Nova Iorque, assinou a Convenção sobre os Direitos das Pessoas com Deficiência e o seu Protocolo Facultativo. Cabe ressaltar que a Convenção sobre os Direitos das Pessoas com Deficiência e seu Protocolo Facultativo passou a ser o primeiro Tratado Internacional a ingressar na nossa ordem jurídica interna com status de equivalência constitucional, por ter sido aprovado nos exatos termos da regra imposta pelo $\S 3^{\circ}$ do art. $5^{\circ}$ da Constituição Federal. A principal contribuição desta Convenção é a positivação da mudança de paradigma da visão da deficiência no mundo, que passa do modelo médico, no qual a deficiência é tratada como um problema de saúde, para o modelo social dos direitos humanos, no qual a deficiência é resultante de uma equação que tem duas variáveis, quais sejam as limitações funcionais do corpo humano e as barreiras impostas pelo ambiente exclusivo ao indivíduo.

A Convenção, ao ter reconhecido o modelo social como o mais novo paradigma para conceituar as pessoas com deficiência, embasou também a consolidação da acessibilidade positivada como princípio fundamental para que esse segmento concretize seus direitos fundamentais em todos os aspectos de suas vidas. Assim, a Convenção reconheceu 
expressamente à importância da acessibilidade aos meios físico, social, econômico e cultural, à saúde, à educação, e à informação e comunicação, para possibilitar às pessoas com deficiência o pleno gozo de todos os direitos humanos e liberdades fundamentais.

Assim, para que a pessoa com deficiência exerça de forma efetiva o direito à acessibilidade, a Convenção determinou também em seu artigo $9^{\circ}$, que os Estados estarão obrigados a tomar medidas apropriadas para assegurar a sua efetivação, em igualdade de oportunidades com as demais pessoas, ao meio físico, ao transporte, à informação e comunicação, bem como a outros serviços e instalações abertos ao público ou de uso público, tanto na zona urbana como na rural. Também se exige a acessibilidade no que diz respeito a informações, comunicações e outros serviços, inclusive serviços eletrônicos e serviços de emergência.

Com a entrada em vigor da Lei Brasileira de Inclusão da Pessoa com Deficiência (Estatuto da Pessoa com Deficiência) - Lei n ${ }^{\circ}$ 13.146, de 07 de julho de 2015, ampliou-se no plano infraconstitucional, a Convenção sobre os Direitos das Pessoas com Deficiência, e, no que tange ao tema acessibilidade, ratifica e especifica direitos antes já presentes no ordenamento pátrio. E, na tentativa de cumprir o objetivo da acessibilidade veio a Lei $\mathrm{n}$. 13.146/2015, em seu art. $3^{\circ}$, I, o que considera acessibilidade: a possibilidade e condição de alcance para utilização, com segurança e autonomia, de espaços, mobiliários, equipamentos urbanos, edificações, transportes, informação e comunicação, inclusive seus sistemas e tecnologias, bem como de outros serviços e instalações abertos ao público, de uso público ou privados de uso coletivo, tanto na zona urbana com na rural, por pessoa com deficiência ou com mobilidade reduzida.

E, abrindo o Capítulo referente à acessibilidade, o art. 53 da Lei n. 13.146/2015 asseverou que a acessibilidade é o direito que garante à pessoa com deficiência ou com mobilidade reduzida viver de forma independente e exercer seus direitos de cidadania e de participação social. Em seu artigo 55, determinou que a concepção e a implantação de projetos que tratem do meio físico, de transporte, de informação e comunicação, inclusive de sistemas e tecnologias da informação e comunicação, bem como de outros serviços, equipamentos e instalações abertos ao público, de uso público ou privado de uso coletivo, seja na zona urbana ou na zona rural, deverão atender aos princípios do desenho universal.

A expressão desenho universal ou universal design foi cunhada pelo arquiteto Ron Mace, que articulou e influenciou uma mudança nos paradigmas dos projetos de arquitetura e 
design (CAMBIAGHI, 2007, p. 71). Segundo ele, o desenho universal é utilizado para descrever o conceito de projetar e construir produtos ou ambientes para ser utilizável, na maior medida possível, por todos (MACE, 2017). O objetivo principal dessa nova concepção, segundo assevera José Antônio Lanchotti (2005, p. 105), é o de:

simplificar as ações do dia a dia de todas as pessoas, produzindo ambientes, objetos e comunicações que possam ser utilizados por todas as pessoas sem precisar de custos extras com adaptações ou adequações, beneficiando usuários de várias idades e habilidades.

A definição de desenho universal veio expressa na NBR 9050/2004 da ABNT e no art. $8^{\circ}$, IX, do Decreto n. 5.296/2004. E, encontra-se atualmente a definição de desenho universal na Lei n. 13.146/2015, em seu art. 3º, II, como sendo a concepção de produtos, ambientes, programas e serviços a serem usados por todas as pessoas, sem necessidade de adaptação ou de projeto específico, incluindo os recursos de tecnologia assistiva.

Em síntese, determina o Estatuto, à luz do que vem disposto na Constituição, especialmente com a alteração promovida pela Convenção da ONU, que um espaço será acessível (ambiente urbano/rural ou edificação) quando todos puderem ingressar, circular e utilizar todos os ambientes e não apenas parte deles. Pois, a essência do desenho universal está no propósito de estabelecer acessibilidade integrada a todos, sejam ou não pessoas com deficiência. "O termo acessibilidade representa uma meta de ampla inclusão, não um eufemismo". (CAMBIAGHI, 2007, p. 73)

Sendo assim, é inconcebível, atualmente, que obras continuem sendo construídas ou reformadas ou projetos elaborados sem contemplar os princípios do desenho universal e, consequentemente, sem assegurar a acessibilidade. Portanto, toda e qualquer construção, reforma ou ampliação tanto públicas quanto privadas de uso coletivo, como vias e espaços públicos, deverão estar acessíveis.

\section{A ACESSIBILIDADE NAS CIDADES}

Conforme pudemos constatar a acessibilidade ao meio urbano, bem como nas edificações, nos transportes e nas suas mútuas interações é uma exigência constitucional que surge, atualmente, de acordo com a Convenção sobre o Direito das Pessoas com Deficiência, como um direito fundamental, sobretudo para a pessoa com deficiência.

Estabelece-se que o direito à acessibilidade, foi materializado nos artigos 227, parágrafo segundo e 244, do texto original da Constituição Federal de 1988. Para dar eficácia 
a esses dispositivos constitucionais, o legislador ordinário elaborou diversas leis e decretos, notadamente a Lei Brasileira de Inclusão da Pessoa com Deficiência, que reservou um capítulo específico para o tema.

Como vimos, a falta de acessibilidade nos espaços públicos, nas vias públicas, no mobiliário urbano, nos transportes, nos meios de comunicação, na informação e tecnologias e sinalizações, faz com que essas pessoas fiquem confinadas em suas casas ou em clínicas.

No federalismo brasileiro, a nossa Constituição estabeleceu um sistema de repartição de competências entre a União, Estados, Distrito Federal e Municípios, dotando-os de autonomia política, financeira, administrativa e legislativa. O sistema de repartição adotado pela Constituição Federal entre as entidades da Federação, é bastante complexo, não iremos nesse relatório abordar tal questão de forma detalhada, porém, faz-se necessário breves considerações no tocante a competência dos entes federativos ao dever de efetivar a acessibilidade.

Considerando que a Lei Maior traçou regras de competência normativa e executiva relativa à proteção da pessoa com deficiência, circunscrita na responsabilidade da União, Estados, Distrito Federal e Municípios (art. 24, inciso XIV e artigo 23, II), e, considerando também que a Constituição Federal assegurou a todos esses entes a competência de implementarem o desenvolvimento urbano, porque a todas elas interessa a ordenação físicosocial do território nacional, é dever, portanto, da União, dos Estados, do Distrito Federal e dos Municípios assegurarem acessibilidade, pois sua abordagem se prende, principalmente ao espaço físico do meio urbano.

Não obstante, é o Município o principal responsável pela tomada de decisões e das ações executórias das políticas de acessibilidade. É o poder público municipal, a esfera de governo mais próxima do cidadão, e, assim, da vida de todos. Essa proximidade permite, ainda, maior articulação entre os vários segmentos que compõem a sociedade local e, também, a participação e acompanhamento das associações de pessoas com deficiência, de organizações não governamentais, de representantes dos interesses privados na elaboração, implementação e avaliação de políticas urbanas.

Afinal, cabe aos Municípios a promoção do adequado ordenamento territorial, mediante planejamento e controle do uso, do parcelamento e da ocupação do solo, sendo portanto, o responsável por formular a política urbana e fazer cumprir, as funções sociais da cidade, possibilitando o acesso e garantindo o direito a todos que nela vivem à moradia, aos 
serviços e equipamentos urbanos, ao transporte público, ao saneamento básico, à saúde, à educação, à cultura e ao lazer e, notadamente, o acesso ao meio físico aos que vivem nas cidades. (art. 30, VIII e 1821, da CF).

É notório que no Brasil, a concentração da população na área urbana ocorreu de forma acelerada e desordenada, acarretando uma série de consequências deletérias para as cidades, inclusive, vivenciadas ainda hoje. Na maioria de nossas cidades os benefícios da urbanização são inacessíveis para uma boa parcela de seus habitantes. Dentre essa parcela que não utiliza os benefícios da urbanização, estão as pessoas com deficiência ou mobilidade reduzida que ainda não conseguem usufruir, no nosso estudo, do direito de circularem de forma livre e segura pelos espaços da cidade. (LEITE, 2012, p. 248)

Esta foi também sem dúvida, uma das razões para o surgimento por ocasião do processo constituinte no final da década de 1980, do movimento da Reforma Urbana, que apresentou, por meio da emenda popular, o desejo de introduzir do direito à cidade no ordenamento brasileiro como um direito fundamental inerente a todas as pessoas que vivem na cidade. Assim, o direito à cidade é compreendido como um conjunto de propostas defendidas, através dessa emenda popular, para introdução do capítulo da política urbana na Constituição Federal de 1988, que visava além de ampliar os direitos fundamentais das pessoas que vivem nas cidades; estabelecer o regime da propriedade urbana e do direito de construir, condicionando o exercício do direito de propriedade à função social, como fundamento e garantia dos direitos urbanos; efetivar o direito à cidade mediante a adoção de instrumentos eficazes de política urbana; assegurar que a cidade atenda a suas funções sociais como promover a justa distribuição dos bens e serviços urbanos e de preservar o meio ambiente; conferir ao Município a competência e do dever de aplicar, de acordo com a realidade local, os instrumentos da política urbana, devendo, para cada situação concreta, utilizar o instrumento mais adequado e, estabelecer os instrumentos de participação popular visando assegurar a Gestão Democrática da cidade como forma de exercer a cidadania. (SAULE JUNIOR, 2007, p. 33-34)

Nesse cenário, a Constituição Federal de 1988 inovou ao incluir o capítulo específico sobre a política urbana, estabelecendo um conjunto de princípios, responsabilidades, obrigações do Poder Público e de instrumentos jurídicos e urbanísticos a serem aplicados e respeitados, com o objetivo de reverter o quadro das desigualdades sociais nas cidades, possibilitando uma condição de vida digna para a população urbana. 
Assim, o artigo 182 da CF 88 abre o capítulo da política urbana, sendo a matriz para a disciplina do direito urbanístico e, consequentemente para implementar o direito à cidade.

É fato que os dispositivos contidos no capítulo da política urbana, dependiam de uma legislação complementar específica, para a qual foram necessários onze anos de mobilizações, elaborações e negociações, até a aprovação da Lei n. 10.257, em 10 de julho de 2001, denominada Estatuto da Cidade, que regulamentou os artigos 182 e 183 da CF.

Não podemos perder de vista que o reconhecimento do direito à cidade, no campo jurídico, se deu com a edição desta Lei. Sua instituição foi veiculada no bojo do inciso I do artigo 2 da Lei 10.257/2001, no âmbito das diretrizes gerais que devem ser promovidas para a garantia desse direito. Esse artigo definiu o direito às cidades sustentáveis, entendido como o direito à terra urbana, à moradia, ao saneamento, à infraestrutura urbana, ao transporte, aos serviços públicos, ao trabalho, ao lazer, para as presentes e futuras gerações. O direito às cidades sustentáveis vai ao encontro do direito à acessibilidade, afinal, as pessoas com deficiência ou mobilidade reduzida também deveriam ter direito a utilizar dos equipamentos urbanos e comunitários, ao transporte público e aos serviços públicos adequados aos seus interesses e necessidades.

O Estatuto da Cidade é o novo marco legal urbano para a ação dos governos municipais, os quais buscam enfrentar os graves problemas urbanos, sociais e ambientais que atingem enormes parcelas da população brasileira; é de suma importância o papel dos municípios na formulação e condução do processo de gestão das cidades, estabelecendo diretrizes para nortear a elaboração de políticas urbanas. Consolida-se e amplia-se a competência jurídica da ação municipal, instituída pela Constituição, pela Lei 10.257/01 e na Lei n. 12.587/2012, inclusive para efetivar a acessibilidade nos espaços da cidade (Lei 10.098/00).

\section{A OBSERVAÇÃO EMPÍRICA SOBRE A ACESSIBILIDADE EM BAURU}

A partir dessas considerações, para atingirmos os objetivos da nossa pesquisa, que foi analisar a doutrina e as legislações tanto no plano constitucional, infraconstitucional e, especificamente as leis do Município de Bauru que asseguram o direito a acessibilidade para as pessoas com deficiência e verificar de que maneira o Poder Público municipal de Bauru, na prática tem efetivado esse direito para as pessoas com deficiência; utilizamos numa primeira etapa o levantamento bibliográfico e a análise de doutrinas e legislações no âmbito 
constitucional, infraconstitucional a partir da Constituição federal de 1988 e, leis do Município de Bauru no período de 1999 a 2019, que resultou em um diagnóstico comparativo das condições de acessibilidade na cidade de Bauru, no que tange às barreiras/obstáculos físicos, que acabam por impedir as pessoas com deficiências de ir, vir e circular de maneira livre e autônoma em igualdade de condições com as demais pessoas.

No tocante ao Poder Público de Bauru, apuramos que houve a publicação de uma série de leis e decretos municipais que asseguram a acessibilidade no Município, especialmente relacionada às seguintes situações: educação, licenciamento de obras e edificações, calçadas, idosos, mulheres grávidas e crianças. A sistematização e análise que segue foi feita considerando o ano de publicação das referidas normas.

No ano de 1999, foi publicada a Lei $\mathrm{n}^{\circ} 4472^{3}$ que assegurou matrícula ao estudante portador de deficiência locomotora na Escola Municipal mais próxima de sua residência. Ainda no mesmo ano, foi publicada a Lei $n^{\circ} 4475^{4}$ que dispõe sobre a adaptação e acessibilidade das pessoas portadoras de deficiências aos edifícios públicos, logradouros públicos, vias públicas, mobiliários e equipamentos urbanos, competindo ao Município através das Secretarias de Planejamento e de Obras proporcionar, fiscalizar, facilitar, garantir e construir adequadamente a acessibilidade ao meio físico urbano às pessoas portadoras de deficiências (PPDs) e na aprovação dos projetos de parcelamento do solo urbano de construção e reforma de quaisquer Edifícios Públicos, Logradouros Públicos, Vias Públicas, Mobiliários e Equipamentos Urbanos ficando condicionada ainda à observância da norma NBR 9050 de setembro de 1994 da Associação Brasileira de Normas Técnicas - ABNT - ou da norma mais atualizada, além das exigências do Código de Obras do Município, instituído pela Lei Municipal $n^{\circ} 2371$, de 1982, e de acordo com o disposto no artigo 227, parágrafo $1^{\circ}$, inciso II, e parágrafo $2^{\circ}$, combinado com os artigos 23, inciso II, 24 e 244 da Constituição Federal.

Em 2001, foi publicada a Lei ${ }^{\circ} 4727^{5}$ que criou a Comissão Técnica para que Poder Público Municipal realize e fiscalize as adaptações das acessibilidades voltadas para a pessoa portadora de deficiência e à pessoa idosa. Esta Lei foi alterada pela Lei n. 5851 que criou a

\footnotetext{
${ }^{3}$ Disponível:https://sapl.bauru.sp.leg.br/consultas/norma_juridica/norma_juridica_mostrar_proc?cod_norma=465 1 Acesso em 30 out 2020

${ }^{4}$ Disponível:https://sapl.bauru.sp.leg.br/consultas/norma_juridica/norma_juridica_mostrar_proc?cod_norma=465 $\frac{3}{5}$

${ }^{5}$ Disponível:https://sapl.bauru.sp.leg.br/consultas/norma_juridica/norma_juridica_mostrar_proc?cod_norma=490 9. Acesso em 30 out 2020
} 
Comissão Técnica que tem como objetivo realizar e fiscalizar as adaptações das acessibilidades voltadas para a pessoa portadora de deficiência.

A Lei $\mathrm{n}^{\circ} 4798$ de $2002^{6}$ dispõe sobre normas de acessibilidade às pessoas portadoras de deficiência a diversos locais, condicionando a aprovação dos projetos de parcelamento do solo urbano, de construção e reforma de qualquer edifício ao cumprimento da NBR 9050 da ABNT, além das exigências do Código de Obras do Município.

Dispondo sobre a acessibilidade aos portadores de deficiência visual em elevadores, foi publicada a Lei $\mathrm{n}^{\mathbf{0}} 4979$ de $2003^{7}$, determinado que os elevadores instalados ou a serem instalados em edifícios públicos ou privados deverão possuir marcações em Braille nas botoeiras do carro e nas botoeiras de pavimento, podendo as marcações ser em placa de metal rígido ou plástico rígido, gravadas e permanentemente fixadas. Em dezembro do mesmo ano, essa Lei foi alterada pela de no. 5066, para determinar que a não observância da determinação na Lei n. 4979, poderá acarretar a pena de advertência, multa, interdição e não aprovação dos projetos de construção e não-concessão do HABITE-SE.

A Lei $n^{\circ} 7028$ de $2017^{8}$ disciplina as regras gerais para o licenciamento de obras e edificações no Município de Bauru, determinando que os procedimentos de aprovação e licenciamento estabelecidos por esta lei aplicam-se a todas as obras e edificações.

Em 2019, foi publicada a Lei das Calçadas - Lei $\mathrm{n}^{\mathrm{o}} 7181^{9}$ que disciplina o uso, a construção e a manutenção dos passeios e logradouros públicos no Município de Bauru. Segundo a Lei, entende-se como passeio público a parte da via, normalmente segregada e em nível diferente, não destinada à circulação de veículos, reservada ao trânsito de pedestres e, quando possível, à implantação de mobiliário urbano, sinalização, vegetação e outros afins descrito nesta Lei. Sendo de obrigação dos proprietários ou possuidores de imóveis urbanos, a qualquer título, para imóveis edificados ou não: construir o passeio público na extensão correspondente à(s) sua(s) testada(s); reparar o passeio público sempre que constatados buracos, pedras faltantes ou outras incidências que possam oferecer risco ao pedestre; manter o passeio público limpo, desobstruído, capinado e drenado, respondendo por situações de

\footnotetext{
${ }^{6}$ Disponível:https://sapl.bauru.sp.leg.br/consultas/norma_juridica/norma_juridica_mostrar_proc?cod_norma=498 0 Acesso em 30 out 2020

${ }^{7}$ Disponível:https://sapl.bauru.sp.leg.br/consultas/norma_juridica/norma_juridica_mostrar_proc?cod_norma=516 0 . Acesso em 30 out 2020

${ }^{8}$ Disponível:https://sapl.bauru.sp.leg.br/consultas/norma_juridica/norma_juridica_mostrar_proc?cod_norma=119 15. Acesso em 30 out 2020

${ }^{9}$ Disponível: https://sapl.bauru.sp.leg.br/pysc/download_norma_pysc?cod_norma=12190\&texto_original=1 Acesso em 30 out 2020
} 
abandono ou que ensejam sua utilização como depósito de lixo, detritos ou resíduos de qualquer natureza. Ficando dispensado da obrigação de construção de passeio público o proprietário ou possuidor de imóvel localizado em via desprovida de guias.

A Lei nº 7198 de 2019 veio para dar aos idosos, grávidas, pessoas com crianças no colo e pessoas com deficiência ou mobilidade reduzida temporária ou permanente nos assentos do transporte coletivo, determinando que todos os assentos dos veículos do transporte coletivo público da Cidade de Bauru, passam a ser preferenciais a idosos com idade igual ou superior a 60 anos, mulheres grávidas, pessoas com crianças no colo e pessoas com deficiência ou mobilidade reduzida, temporária ou permanente.

No ano de 2020, foi publicada a Lei $\mathrm{n}^{\mathrm{o}} 7321^{10}$ dispõe sobre o Programa Parada Segura, que estabelece norma para o desembarque de mulheres, idosos ou pessoas com mobilidade reduzida no transporte coletivo urbano, em período noturno. Os condutores dos veículos utilizados para a prestação de serviço de transporte coletivo urbano no Município de Bauru deverão, no período das 22 (vinte e duas) horas às 5 (cinco) horas, parar os veículos para possibilitar o desembarque de pessoas do sexo feminino, idosos ou pessoas com mobilidade reduzida, em qualquer local onde seja permitido estacionamento, no trajeto regular da respectiva linha, mesmo que nele não haja ponto de parada regulamentado. A solicitação de Parada Segura deverá ser previamente informada ao motorista. As paradas fora dos pontos podem ser solicitadas aos condutores todos os dias, das $22 \mathrm{~h}$ às $5 \mathrm{~h}$.

Apesar da farta legislação dispondo sobre a acessibilidade na cidade de Bauru, será que seus espaços ao meio físico estão acessíveis?

Para responder a essa questão, e atingir um dos objetivos desta investigação: verificar se na prática o Município de Bauru tem concretizado o direito à acessibilidade, passamos para a segunda etapa de nossa investigação, na qual realizou-se a observação empírica e sistemática com fotos e fichas cadastrais (foram fotografadas 38 aspectos) para compilar, avaliar e identificar a atual situação dos projetos implantados e/ou adaptados com observância do desenho universal do espaço público de Bauru, abrangendo uma área de cerca de $2 \mathrm{~km}$ de raio da região central desta cidade, conforme a figura 1, no período de junho a agosto de 2019, nas seguintes variáveis: presença de faixas para orientar as pessoas com deficiência

\footnotetext{
${ }^{10}$ Disponível: https://sapl.bauru.sp.leg.br/pysc/download_norma_pysc?cod_norma=12431\&texto_original=1 Acesso em 30 out 2020
} 
visual, de pisos adequados para quem utiliza cadeiras de rodas ou bengalas, de degraus ou rampas com corrimão e, de acesso facilitado para ingressar nos locais.

Figura 1 - Mapa da Região Central observada em Bauru

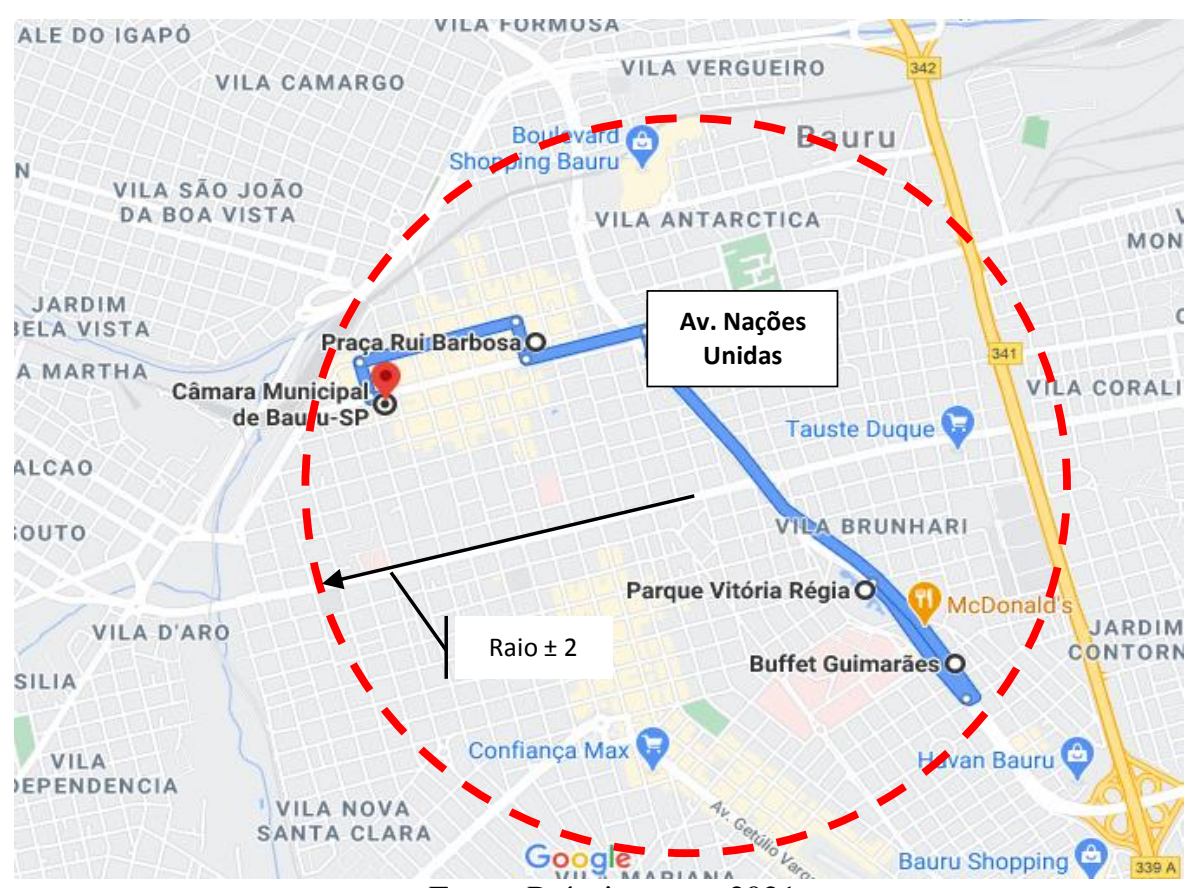

Fonte: Próprio autor, 2021

As figuras 2 a 5 foram capturadas do calçadão da Rua Batista de Carvalho, um ponto comercial do centro da cidade, no parque Vitória Régia e em pontos próximos ao local, na Avenida Nações Unidas. Elas apresentam alguns aspectos destes locais a fim de se verificar a acessibilidade destes.

Figura 2 - Parque Vitória Régia

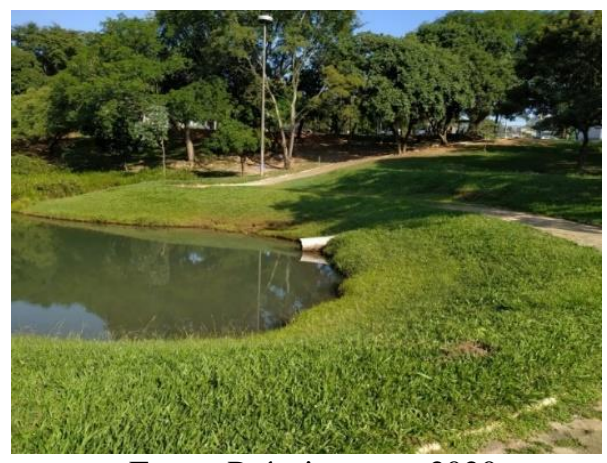

Fonte: Próprio autor, 2020
Figura 3 - Parque Vitória Régia

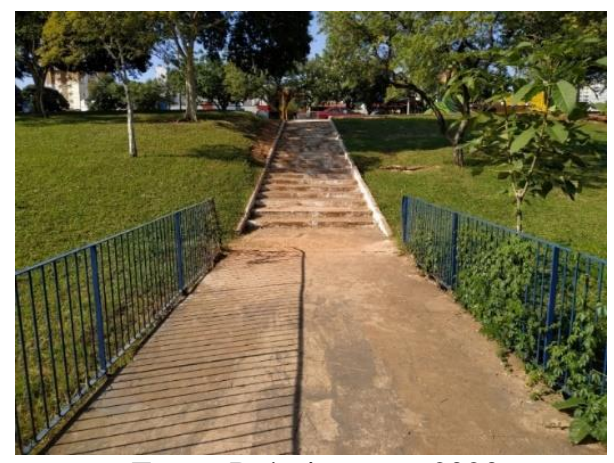

Fonte: Próprio autor, 2020 
Com relação ao Parque Vitória Régia, figuras 4 e 5, destacam-se a ausência de faixas na calçada que orientam pessoas com deficiência visual, além de pisos inadequados para uso de pessoa com deficiência física, que utiliza cadeiras de rodas ou bengalas.

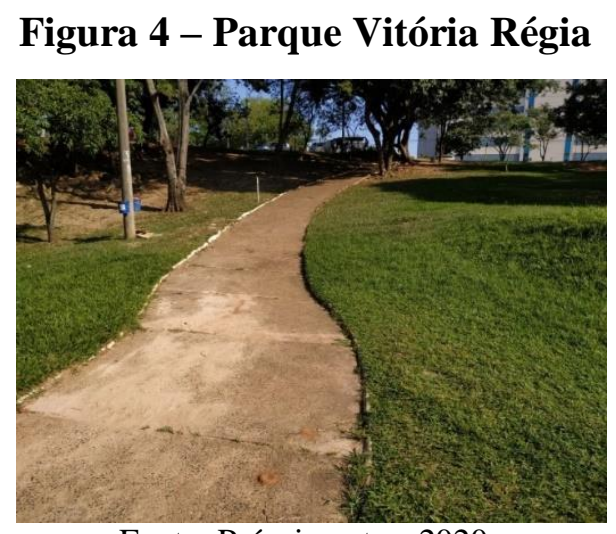

Fonte: Próprio autor, 2020

\section{Figura 5 - Parque Vitória Régia}

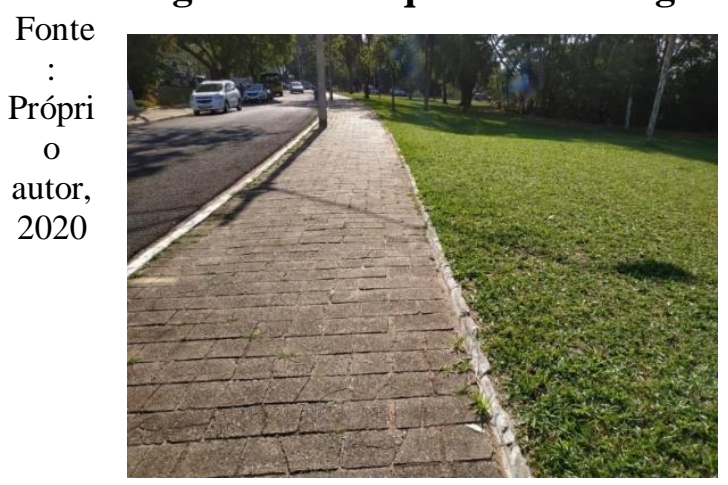

A figuras 6 demonstra a fachada do Buffet Guimarães, ponto comercial na Avenida Nações Unidas, em Bauru, onde não é possível identificar pontos acessíveis para cadeirantes, por exemplo. O local conta com um número significativo de degraus, o que dificulta o acesso de algumas pessoas. Andando pelas redondezas do local, não foi possível identificar outra entrada e, no momento do registro, não havia ninguém no estabelecimento que pudesse esclarecer essas informações.

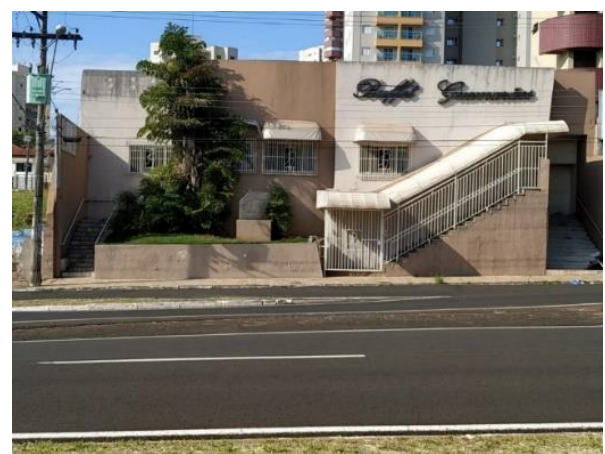

Figura 6 - Buffet Guimarães

Fonte: Próprio autor, 2020
Figura 7- Avenida Nações Unidas

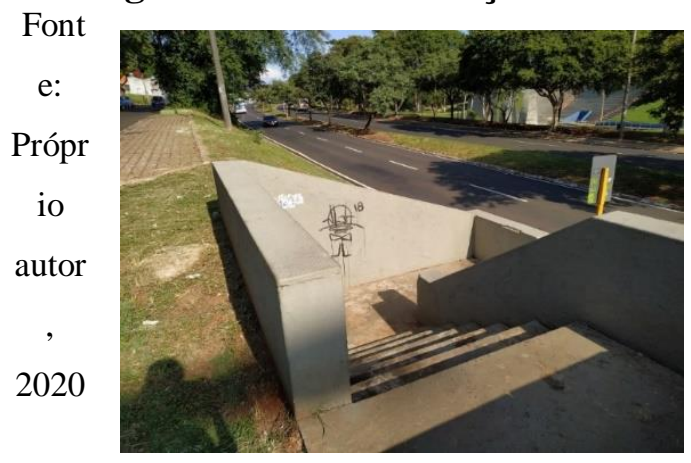

A figura 7 refere-se ao ponto de acesso para pedestres entre a pista local e a Avenida das Nações. Como é possível perceber, o local conta apenas com degraus, sem registros de rampas ou corrimão nas proximidades. 
Figura 8 - Praça Rui Barbosa na área central de Bauru

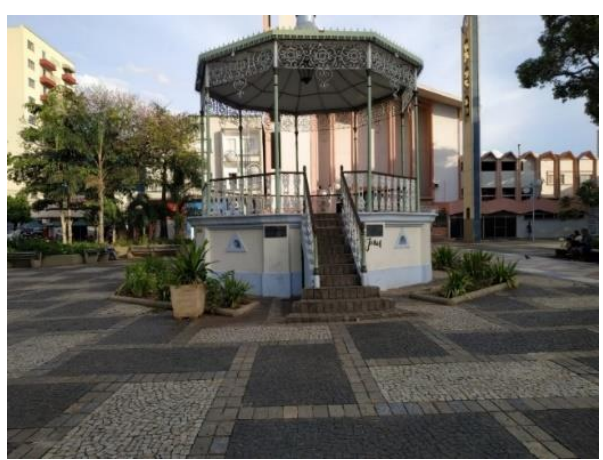

Figura 9 - Centro de Bauru

$\begin{array}{cc}\text { Font } & \\ \text { e: } & \\ \text { Próp } & \text { Font } \\ \text { rio } & \text { e: } \\ \text { auto } & \text { Próp } \\ \text { r, } & \text { ró } \\ 2020 & \text { rio } \\ & \text { auto } \\ & \text { r, } \\ & 202\end{array}$

202

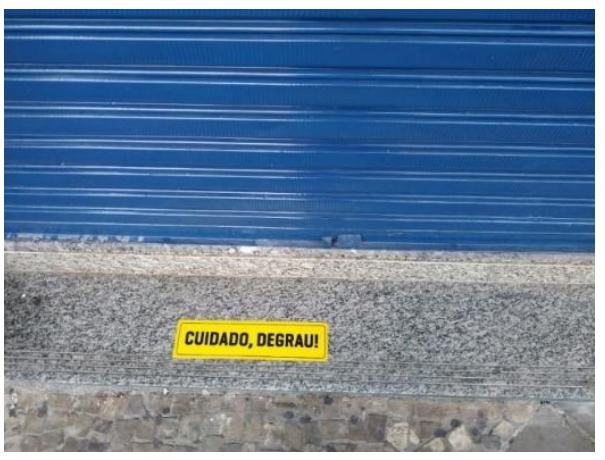

0

A figura 8 apresenta um aspecto da Praça Rui Barbosa no centro de Bauru, mas também não possui o acesso facilitado, assim como em alguns estabelecimentos, como registrado na figura 9, que orienta o "perigo" para um local de acesso restrito, apesar de não ter sido identificada a exata necessidade da informação.

Figura 10 - Câmara Municipal

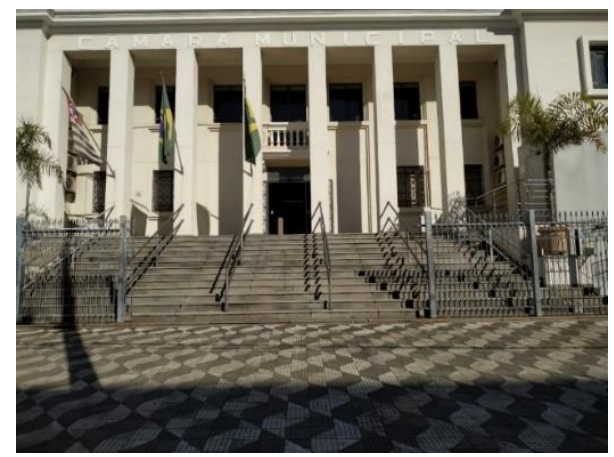

Fonte: Próprio autor, 2020
Figura 11 - Câmara Municipal

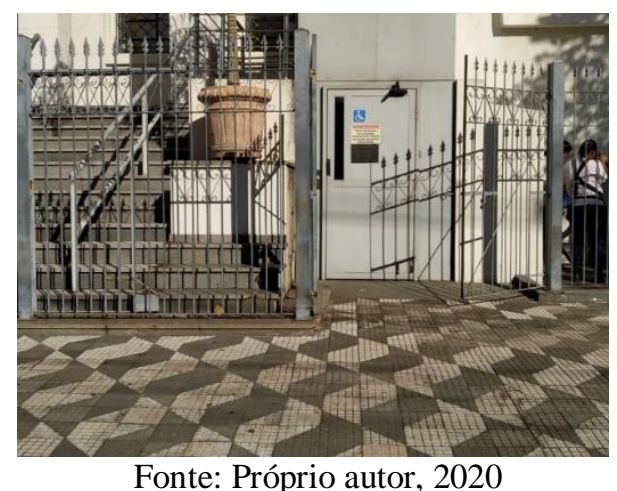

Fonte: Próprio autor, 2020

As figuras 10 e 11 demonstram aspectos da Câmara Municipal, que é um prédio público e que conta com um número significativo de degraus, o que dificulta o acesso de pessoas com deficiência física e de algumas pessoas com mobilidade reduzida, por exemplo, os que utilizam muletas. Essa situação parece-nos inconcebível, afinal as leis municipais inclusive as que garantem a acessibilidade - não são cumpridas, são promulgadas neste prédio.

\section{CONSIDERAÇÕES FINAIS}

Conforme constatou-se ao longo desse trabalho, a acessibilidade aos edifícios e logradouros públicos, no transporte coletivo e nas suas mútuas interações é regra mínima e básica de cidadania, tanto que, o constituinte a materializou no artigo $227, \S 2^{\circ}$ e no artigo 
244. Para dar eficácia a esses dispositivos constitucionais, foram editadas, dentre outras, a Lei 7.853/89, o Decreto $\mathrm{n}^{\circ} 3.29899$, as Leis $\mathrm{n}^{\circ} 10.04800$ e $\mathrm{n}^{\circ} 10.09800$ e o Decreto $\mathrm{n}^{\circ}$ 5.29604. E, no caso específico de Bauru, nas Leis n ${ }^{\circ} \mathrm{s} 4472 / 99 ;$ 4475/99; 4727/01; 4798/02; 4979/03; 5055/03; 7028/17; 7181/19; 7198/19 e 7321/20. Após a análise das legislações, comparou-se com as do Município de Bauru, concluindo que de uma maneira geral, toda legislação visa garantir a plena integração social da pessoa com deficiência garantindo acessibilidade aos espaços públicos da cidade de Bauru.

A etapa de coleta de dados empíricos, no período de junho a agosto de 2019, apontou inúmeras barreiras físicas nesses espaços, tais como a ausência de faixas na calçada para orientarem as pessoas com deficiência visual, além de pisos adequados para uso de cadeiras de rodas ou bengalas, falta de rampas e de acesso, dentre outras.

De posse desses resultados conclui-se que: viver em cidades -, especificamente no caso de Bauru, continua sendo um desafio para a pessoa com deficiência ou com mobilidade reduzida que, ao se locomoverem e se movimentarem por esses espaços, deparam-se ainda com incontáveis obstáculos físicos. O fato é que quando não há espaços públicos acessíveis para as pessoas com deficiência ou mobilidade reduzida, o local deixa de ser de convívio, de encontro, de troca, para tornar-se de exclusão espacial.

Vemos que, a necessidade de circular está associada ao desejo de realização das atividades sociais, profissionais, culturais, políticas e econômicas necessárias na sociedade. E, as pessoas com deficiência ou mobilidade reduzida deveriam conseguir se movimentar pelos seus espaços com autonomia, segurança e conforto. Sair de sua residência, conseguir chegar até o seu local de trabalho, buscar algum lazer: possibilidades que compõem o direito fundamental de ir, vir, ficar e permanecer.

Portanto, a necessidade de deslocar, de circular, dependerá de como a cidade está organizada territorialmente e vinculada funcionalmente às atividades que se desenvolvem em seu espaço, afinal, quando a cidade não é acessível, não é para todos.

\section{REFERÊNCIAS}

BEZERRA, Rebecca Monte Nunes. A acessibilidade como condição de cidadania. In: GUGEL, Maria Aparecida/ COSTA FILHO, Waldir Macieira da/ RIBEIRO, Lauro Luiz Gomes (Org.). Deficiência no Brasil/ uma abordagem integral dos direitos das pessoas com deficiência. Florianópolis: Obra Jurídica, 2007. 
BRASIL. Ministério das Cidades. Secretaria Nacional de Transporte e da Mobilidade. Brasília, 2015. Disponível no endereço eletrônico: http://planodiretor.mprs.mp.br/arquivos/planmob.pdf Acesso em 21 jul de 2019.

BRASIL. Lei Municipal n. 4472, de 24 de novembro de 1999, dispõe sobre a matricula ao estudante portador de deficiência locomotora na escolha municipal mais próxima de sua residência.

Disponível

em:

https://sapl.bauru.sp.leg.br/consultas/norma juridica/norma juridica mostrar proc?cod norm

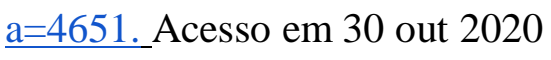

BRASIL. Lei Municipal n. 4475, de 29 de novembro de 1999, que dispõe sobre a adaptação e a acessibilidade das pessoas com deficiências PPDS aos edifícios públicos, logradouros públicos, vias públicas, mobiliário e equipamentos urbanos. Disponível em: https://sapl.bauru.sp.leg.br/consultas/norma_juridica/norma_juridica_mostrar_proc?cod_norm $\underline{a}=4653$.Acesso em 30 out 2020

BRASIL. Lei Municipal n. 4727, de 14 de setembro de 2001, que cria a comissão técnica para que o poder público municipal realize e fiscalize as adaptações das acessibilidades voltadas para a pessoa portadora de deficiência e à pessoa idosa e para melhor implementar as normas da associação brasileira de normas técnicas - ABNT e as demais orientações que esta comissão poderá normatizar para o cumprimento das leis municipais e dá outras providências. Disponível:

https://sapl.bauru.sp.leg.br/consultas/norma juridica/norma juridica mostrar proc?cod norm $\underline{a=4909 .}$. Acesso em 30 out 2020

BRASIL. Lei Municipal n. 4798, de 19 de fevereiro de 2002, que dispõe sobre normas de acessibilidade às pessoas portadoras de deficiência a diversos locais que especifica e dá outras providências.

Disponível:

https://sapl.bauru.sp.leg.br/consultas/norma_juridica/norma_juridica_mostrar_proc?cod_norm $\underline{a}=4980$. Acesso em 30 out 2020

BRASIL. Lei Municipal n. 4979, de 15 de maio de 2002, que dispõe sobre a acessibilidade de portadores de deficiência visual em elevadores e dá outras providências. Disponível :

https://sapl.bauru.sp.leg.br/consultas/norma juridica/norma juridica mostrar proc?cod norm $\underline{a=5160}$ Acesso em 30 out 2020 
BRASIL. Lei Municipal n; 7028, de 21 de dezembro de 2017, que dispõe sobre o licenciamento de obras e edificações no Município de Bauru (Novo Código de Obras). Disponível:

https://sapl.bauru.sp.leg.br/consultas/norma_juridica/norma_juridica_mostrar_proc?cod_norm $a=11915$ Acesso em 30 out 2020

BRASIL. Lei Municipal n. 7181, de 04 de fevereiro de 2019, que disciplina o uso, a construção e a manutenção dos passeios e logradouros públicos no Município de Bauru. Disponível:

https://sapl.bauru.sp.leg.br/pysc/download norma pysc?cod norma=12190\&texto original=1 Acesso em 30 out 2020

BRASIL. Lei Municipal no 7321, de 05 de fevereiro de 2020, que dispõe sobre o Programa Parada Segura, que estabelece norma para o desembarque de mulheres, idosos ou pessoas com mobilidade reduzida no transporte coletivo urbano, em período noturno, no Município de Bauru dá outras providências. Disponível: https://sapl.bauru.sp.leg.br/pysc/download_norma_pysc?cod_norma=12431\&texto_original=1 Acesso em 30 out 2020

CAMBIAGHI, Silvana Serafino. Desenho universal: métodos e técnicas para arquitetos e urbanistas. São Paulo: Editora Senac São Paulo, 2007.

FILHO, Gildo Magalhães dos Santos. Comitê brasileiro de acessibilidade - CB 40. In: Município acessível ao cidadão. São Paulo, Fundação Prefeito Faria Lima - CEPAM, 2001.

GIL, M. A., 2007. Acessibilidade, inclusão social e desenho universal: tudo a ver. Disponível em <http://www.bengalalegal.com/martagil.php> Acesso em 05 dez 2019.

GUIMARÃES, Marcelo Pinto. Desenho universal é design universal: conceito ainda a ser seguido pelas normas técnicas 9050 e pelo Decreto-lei da Acessibilidade. Disponível em: Portal Vitruvius em: htpp//www.vitruvius.com.br/arquitetos/arq096/arq096_03.asp Acessado em 10 de jan de 2018.

GUIMARÃES, Marcelo Pinto. Acessibilidade: diretriz para a inclusão. Disponível em: http//www.saci.org.br/modulo=akemi\&parâmetro=2248 Acessado em 10 jan de 2018. 
LANCHOTI, José Antônio. Critérios de desempenho da mobilidade urbana no espaço urbano construído como avaliadores da cidade acessível: o caso de Ribeirão Preto - SP. 2005. Tese (Doutorado em Arquitetura e Urbanismo) - Universidade de São Paulo, São Paulo: 2005.

LEITE, Flávia Piva Almeida. O município acessível à pessoa portadora de deficiência- O direito à eliminação das barreiras arquitetônicas. São Paulo: RCS, 2007.

LEITE, Flávia Piva Almeida. Cidades acessíveis. 1ª edição. São Paulo: SRS Editora, 2012.

LEITE, Flávia Piva Almeida Leite; COSTA FILHO, Waldir Macieira da; RIBEIRO, Lauro Luiz Gomes (Coord.). Comentários ao estatuto da pessoa com deficiência. São Paulo: Saraiva, 2016.

MACE, Ron. The center universal desing. About Rom Mace. Inernet: https://projects.ncsu.edu/ncsu/design/cud/about_us/usronmace.htm Acessado em 21/04/2020. Acesso em 25 jul 2019.

OSÓRIO, Letícia Marques. Direito à cidade como direito humano coletivo. In: ALFONSIN, Betânia. FERNANDES, Edesio (Org). Direito Urbanístico: Estudos brasileiros e internacionais. Belo Horizonte: Del Rey, 2006.

SASSAKI, Romeu Kazumi. Inclusão - construindo uma sociedade para todos. $3^{\mathrm{a}}$ edição. Rio de Janeiro: Editora WVA, 1999.

SASSAKI, Romeu Kazumi. Conceito de acessibilidade. Disponível em htpp://www.escoladagente.org.br . Acesso em 10 de mar de 2018.

SAULE JUNIOR, Nelson. A relevância do direito à cidade na construção de cidades justas, democráticas e sustentáveis. In: SAULE JUNIOR, Nelson (Org), Direito urbanístico: vias jurídicas das políticas urbanas. Porto Alegre: Sergio Antonio Fabris, 2007.

SILVA, José Afonso da. Direito urbanístico brasileiro. $5^{\text {a }}$ edição, revista e atualizada. São Paulo: Malheiros, 2006. 